Editorial

\title{
Boundary Spanning in Sport for Development: Opening Transdisciplinary and Intersectoral Perspectives
}

\author{
Reinhard Haudenhuyse ${ }^{1, *}$, John Hayton ${ }^{2}$, Dan Parnell ${ }^{3}$, Kirsten Verkooijen ${ }^{4}$ and Pascal Delheye ${ }^{5}$ \\ ${ }^{1}$ Faculty of Physical Education and Physiotherapy, Vrije Universiteit Brussel, 1050 Brussels, Belgium; \\ E-Mail: reinhard.haudenhuyse@vub.be \\ 2 Department of Sport, Exercise and Rehabilitation, Northumbria University, Newcastle upon Tyne, NE1 8SG, UK; \\ E-Mail: john.w.hayton@northumbria.ac.uk \\ ${ }^{3}$ University of Liverpool Management School, University of Liverpool, Liverpool, L69 7ZH, UK; \\ E-Mail: d.parnell@liverpool.ac.uk \\ ${ }^{4}$ Chair Group Health and Society, Wageningen University \& Research, 6700 Wageningen, The Netherlands; \\ E-Mail: kirsten.verkooijen@wur.nl \\ ${ }^{5}$ Department of Political Sciences, Ghent University, 9000 Ghent, Belgium; E-Mail: pascal.delheye@ugent.be \\ * Corresponding author
}

Submitted: 29 July 2020 | Published: 17 August 2020

\begin{abstract}
We can no longer claim that academic interest in the area of sport and social inclusion is lacking. Dedicated books, special issues, commissioned reports, and landmark articles on the topic of social inclusion and sport have been produced by devoted scholars. The same can be said for the burgeoning area of sport for development and peace. These relatively young academic fields seem to be struggling to create new fundamental theoretical insights about how organized sport can both act as an inclusive space and as a vehicle for broader developmental outcomes. Despite scholarly advancements, there remains a number of empirical and theoretical gaps. The aim of this special issue is to critically reflect on issues related to sport, development, and inclusion, and to do so via transdisciplinary and intersectoral perspectives. By making such a contribution, we aim to open up new research pathways.
\end{abstract}

\section{Keywords}

inclusion; intersectoral collaboration; sport for development and peace; transdisciplinarity

\section{Issue}

This editorial is part of the issue "Sport for Development: Opening Transdisciplinary and Intersectoral Perspectives" edited by Pascal Delheye (Ghent University, Belgium), Kirsten Verkooijen (Wageningen University \& Research, The Netherlands), Dan Parnell (University of Liverpool, UK), John Hayton (Northumbria University, UK) and Reinhard Haudenhuyse (Vrije Universiteit Brussel, Belgium).

(C) 2020 by the authors; licensee Cogitatio (Lisbon, Portugal). This article is licensed under a Creative Commons Attribution 4.0 International License (CC BY).

\section{Introduction}

We can no longer claim that academic interest in the area of sport and social inclusion is lacking. Dedicated books (e.g., Collins, 2002; Dagkas \& Armour, 2012; Spaaij, Magee, \& Jeanes, 2014), special issues (e.g., Haudenhuyse, 2017; Schaillée, Haudenhuyse, \& Bradt, 2019), commissioned reports (e.g., Coalter, 2005; Donnelly \& Coakley, 2002), and landmark articles (e.g.,
Bailey, 2005; Kelly, 2011; Lawson, 2005) on the topic of social inclusion and sport have been produced by devoted scholars. The same can be said for the burgeoning area of sport for development and peace (see Darnell, 2012, for a critical sociology, and Collison, Darnell, Giulianotti, \& Howe, 2018, for a collection), which even saw the emergence of a dedicated international open access journal: Journal of Sport for Development. So why then another special edition on the topic? 
These relatively young academic fields seem to be struggling to create new fundamental theoretical insights about how organized sport can both act as an inclusive space and as a vehicle for broader developmental outcomes. Despite scholarly advancements, there remains a number of empirical and theoretical gaps. The aim of this special issue is to critically reflect on issues related to sport, development, and inclusion, and to do so via transdisciplinary and intersectoral perspectives. By making such a contribution, we aim to open up new research pathways.

\section{Transdisciplinary and Intersectoral Perspectives}

Often bound within our own discipline (i.e., the broad field of sport and exercise science), research projects are conceptualized and managed in the offices and hallways of Sport, Health, and Kinesiology university departments. For the most part, we publish our work in peerreviewed sport journals wherein journal scope is decided by editorial boards (sometimes almost) entirely made up by sport scientists, and where double-blind peer-reviews are performed by sport scholars. When PhD examination committees are formed, we often invite colleagues from our own fields, thus perpetuating institutional and disciplinary boundaries. And for the most part we present our work at sport scientific conferences.

When respondents and settings are selected for interviews, questionnaires, observations, or focus groups, they mostly are situated within what we could term 'the sport sector.' We do not appear to be interested in people that are in no way involved in sport, although equally relevant insights could be gained about social in-/exclusion or development from involving people that are not doing, providing or managing sport. Linking sport research to multiple life and policy domains is vitally important and should, as such, include studies from a broad inter-sectoral perspective. This would also require a need for different disciplines working together to create new conceptual, theoretical, and methodological innovations that can move beyond discipline-specific approaches to address common problems (Sparkes \& Smith, 2014, p. 242). Such a collaborative and collective approach has been described as transdisciplinary research (Sparkes \& Smith, 2014) and can lead to the development of new theories and synergies of methods in relation to sport, social inclusion, and development.

\section{Muddling through Theoretical Boundaries}

Disciplinary and sectoral 'boundary closure' hinders the generation of new fundamental theoretical insights about how organized sport can act both as an inclusive space and a vehicle for broad developmental outcomes. Questions about how the field could go beyond the status quo are seldom asked. One possible reason for this is a failure of sport scholars to critically engage with new theoretical developments in more mainstream scientific disciplines such as, for example, sociology, educational sciences, economics, political sciences, gender studies, history, business, management, or philosophy. We rarely encounter researchers from such disciplines in our university hallways, doctoral examination juries and viva voces, editorial board meetings, or conferences rooms. When we do draw upon, adapt, or extend 'foreign theories or concepts,' such as, for example, social capital or positive youth development (see Schulenkorf, Sherry, \& Rowe, 2016), we neglect to keep up to speed with the latest theoretical insights and debates on how such theories are contemporarily applied to 'mainstream' issues.

Whilst the term 'development' is often employed within the sport for development literature, it is seldom theoretically and critically unpacked (for exceptions see Black, 2009; Burnett, 2015; Darnell, 2012). Development often slips into becoming a Western (often neo-conservative) hegemonic concept that is viewed as inherently good. Ziai (2013) provocatively wrote that numerous practices that have been carried out in the name of development have not improved but rather deteriorated the human condition. So, we should not consider all development as inherently good. Additionally, unlike the social in- and exclusion duality, there seems to be no counterpart for 'development,' which is indicative for its hegemonic conceptual nature. It becomes even more problematic when the analytical capacity of 'development' is distracted and deemphasized by abbreviated forms such as SfD (i.e., Sport for Development) or SDP (i.e., Sport for Development \& Peace). In a similar vein, most publications on sport and social inclusion do not provide a fundamental debate on what inclusion actually is, nor what the underlying values are that we use to define it (for exceptions see Kelly, 2011; Kingsley \& Spencer-Cavaliere, 2015) and how such values are shaped by the places and backgrounds of sport scholars. If we are to engage in such debates, then we also need to ask ourselves why we prefer to use the term 'social' inclusion, and not, for example, economic, cultural, or societal inclusion?

\section{Why Are We Talking Development and Not Inclusion?}

Before we introduce the selected articles, we must first elaborate on why we chose to incorporate sport for development into the title of this special issue, and not social inclusion. We did not make this decision simply because we favor development over social inclusion. Both concepts suffer from conceptual shallowness and have been criticized for their underlying normative assumptions (Haudenhuyse, 2017; Ziai, 2013). Interestingly enough, and illustrative for the use of normative and un-examined concepts, is that when referring to 'sportfor-good' programs, social inclusion is dominantly used within Global North settings and sport for development (and peace) in the Global 'developing' South. The underlying rationale is: People and societies in the Global 
South need to be developed to become more like the Global North, while people excluded in the Global North 'just' need to be included in an already developed system. With that said, we do see that the term sport for development is increasingly being used to refer to (community) sport programs in the Global North (see D'Angelo, Corvino, Cianci, \& Gozzoli, 2020; Haudenhuyse et al., 2018; Marlier et al., 2020).

The reason we have chosen sport for development is to attract scholars that are active in at least one of these two fields to contribute to a special issue in the journal of Social Inclusion. A cursory view across the titles of the manuscripts that compose this special issue illustrates that both social inclusion and sport for development are included.

\section{Introducing the Selected Papers}

This unique collection of selected articles opens up transdisciplinary and intersectoral perspectives on the role, impact, and study of sport for development. Rather than boundary closers, the authors of each of the selected articles for this special issue can be viewed as academic "boundary spanners" (Williams, 2002). They do so by innovatively combining theoretical perspectives from different scientific disciplines and taking a broadas opposed to a traditional-narrow-sectoral approach in their research on their respective sport topics.

\subsection{Multi-Professional and Intersectoral Approaches}

Chiara D'Angelo, Chiara Corvino, Eloisa Cianca, and Caterina Gozzoli apply a psycho-sociological perspective to explore the importance of multi-professional groups in sport for development projects working with vulnerable youth (D'Angelo et al., 2020). From the interviews with social workers and sport workers, their findings show that belonging to a multi-professional group is a meaningful resource for triggering workers' reflexivity and promoting intersectoral collaboration. Programs are more likely to succeed when professionals and volunteers have the time and space to deal with the unpredictable and volatile nature of young people's lives. This also implies that programs working towards predefined outcomes or 'targets' will exclude the most vulnerable young people (Haudenhuyse, Theeboom, \& Nols, 2012). D'Angelo et al. (2020) found that when social workers and sport workers are embedded in a well-managed multi-professional team, they are not only better equipped to deal with unexpected events and young people's negative emotions, but also have more time to develop meaningful relationships with young people. A major implication for program design that D'Angelo et al. (2020) stress is that professionals also need the space and time for face-to-face contact and interpersonal collaboration.

Using a multiple case study design, Mathieu Marlier, Bram Constandt, Cleo Schyvinck, Thomas De Bock, Mathieu Winand, and Annick Willem interviewed per- sonnel from sport, social, health, cultural, and youth organizations in six disadvantaged communities to investigate how the application of capacity building principles may result in higher sport participation rates (Marlier et al., 2020). The reference to troubled waters in the title refers to the difficulties between different types of organizations in valuing and utilizing one another's skills, experiences, expertise, and resources in order to boost their collective capacities. Importantly, based on the principles of capacity building, Marlier et al. (2020) identify three actions that community sport for development programs can take: (1) establish a mix of sport staff, social workers, and representatives of people in disadvantaged situations (see also the study on multi-professional groups of D'Angelo et al., 2020); (2) help (sport) organizations to cope with financial, organizational, and cultural pressures working in disadvantaged situations; and (3) reinforce sport activities when existing local organizations are not able to fulfil the sporting needs of people in disadvantaged situations. By formulating key implications about how (sport) organizations can include people living in disadvantaged communities, Marlier et al.'s (2020) study makes a valuable contribution to policy and practice.

\subsection{Mechanisms and Outcomes}

Kirsten Verkooijen, Sabina Super, Lisanne Mulderij, Dico de Jager, and Annemarie Wagemakers take on the challenge of evaluating the complexities and intricacies of sport for development programs (Verkooijen, Super, Mulderij, de Jager, \& Wagemakers, 2020). Their study explores the value of using realist (evaluation) interviews to gain insights about mechanisms and outcomes in three different programs aimed at marginalized youth and adults. Realist evaluation superimposes the 'Why did it (not) work' question, as opposed to more traditional 'Did it work' question. This not only allows for the generation of theoretical insights-or how the authors call it "theoretical awareness" (Verkooijen et al., 2020)about the inner workings of sport for development programs, but also assists in the identification of knowledge gaps of program coordinators and practitioners about the evaluated programs. Aligning with the transdisciplinary aim of the special issue, the authors explore the applicability of a conceptual model from the field of social enterprise. Doing so, Verkooijen et al. (2020) construct a program theory for the investigated programs which can be used as a didactical template that practitioners can draw upon to improve their own program design. However, the authors also identify challenges associated with using realist interviews and theory-based methodologies. One of the main challenges is to distinguish between outcomes, mechanisms, and context. For example, an outcome might become part of the context, since programs working with (young) people in challenging settings do not follow a linear trajectory, and nor do their participants. 
In "Where are they now?," Rob Cunningham, Anne Bunde-Birouste, Patrick Rawstorne, and Sally Nathan explore young people's perceptions of how a youthfocused sport-for-social-change programs influenced their life trajectories (Cunningham, Bunde-Birouste, Rawstorne, \& Nathan, 2020). Their research is unique in that past participants of a football-based program were interviewed about the perceived the impact of the program on their lives. Findings from Cunningham et al. (2020) show that the program had played an influential role in the education and career-based choices of past participants. The program also increased participants' social capital (bonding and bridging), and this was especially so for participants who had experienced displacement and trauma as refugees prior to resettlement. In order to have both a broader and more in-depth understanding on the past, present, and future life trajectories of (young) people that have participated in sport for development programs, the authors impress upon readers the importance of longitudinal research.

\subsection{Spaces and Places}

David Ekholm and Magnus Dahlstedt investigate the significance of geographic place in relation to sport for development initiatives (Ekholm \& Dahlstedt, 2020). The authors bring in concepts from urban geography and social policy to explore an important topic that has, to date, not been addressed both in sport for social inclusion and sport for development literature. Based on ethnographic fieldwork and interviews in two urban areas in Sweden, the authors found that the places where sport for development projects are implemented are separated from the rest of society through both material and symbolic borders. From their findings it becomes clear that the significance of place is closely related to how communities and certain demarcated urban disadvantaged areas are problematized and made 'governable' for social interventions. The authors also make evident how underlying discourses from 'the outside' negatively impact urban communities through, for example, forms of stigmatization (e.g., no-go zones) and discrimination (e.g., criminalization of youth). The article points to the paradoxical nature of how sport for development (or inclusion) programs and policies can contribute to the otherness and exclusion of urban communities. One of the major practical implications that emerged was that, together with people living in urban areas, programs also need to work on co-constructing counter-narratives against dominant exclusionary discourses.

In his article, Mark Norman develops some initial theoretical connections between the literatures on sport for development, leisure studies, prison sport, criminology, and human (carceral) geography (Norman, 2020). Norman (2020) argues that since millions of people are held in sites of confinement such as prisons, (asylum) detention centers, and refugee camps, sport for development research needs to connect with this emerging body of literature on sport and incarceration. This will allow for increasing the theoretical depth of sport for development and social inclusion research. Some of the conclusions in Norman's article resonate well with the article of Ekholm and Dahlstedt (2020), particularly in relation to sport-based social inclusion programs geared at youth living in urban disadvantaged areas, that young people can often find themselves confined by the material and symbolic borders of a neoliberal state architecture. Norman (2020) calls for a carceral geography of sport that can lead to a more nuanced theoretical analysis of time, space, social control, and resistance in and through sport for development programs.

Emily Jane Hayday and Holly Collison explore the role of esport as a new sport-based activity to achieve the developmental goals of the sport for development (and peace) movement (Hayday \& Collison, 2020). Using focus groups and interviews with game publishers, sport for development organizations, esports teams, tournament organizers, and gamers, the authors question the utility of esports as a space to enact social inclusion for women and girls. As an analytical transdisciplinary framework to understand gender dynamics, Hayday and Collison (2020) innovatively combine Lefebvre's spatial theory and Bailey's conceptual model of social inclusion. Findings showed that the dominant hypermasculine dynamics of digital platforms contribute to gender inequality and discrimination (e.g., sexism) within such online communities. This is further aggravated and nurtured by corporate business agendas. Hayday and Collison (2020) show that intersectoral collaboration also holds risks and can actually work against inclusionary and developmental agendas (i.e., UN Sustainable Development Goal 5: Empower woman and girls and ensure their equal rights).

\subsection{Disabled Bodies}

In their article "Why can't I play?," Simon Darcy, Janice Ollerton, and Simone Faulkner explore the leisure constraints of children with disabilities in community-based sport clubs and schools through the views of parents, teachers, coaches, and club officials (Darcy, Ollerton, \& Grabowski, 2020). They analyzed their data using a transdisciplinary conceptual framework, combining the social model of disability and the leisure constraints framework. Their research brings a new social lens to reconceptualize and understand intrapersonal, interpersonal, and structural constraints to sport participation for children with disabilities. The authors stress that many impairmentrelated constraints are not internally located with the child, and as such would need to be challenged through interpersonal support and structural changes. Darcy et al. (2020) conclude by outlining the implications of their findings for policy and practice, not only regarding sport, but also health, education, and social work.

The inclusion and the visibility of disabled athletes has recently become a crucial goal for every organizing committee of the Olympic and Paralympic Games. 
Sylvain Ferez, Sébastien Ruffié, Hélène Joncheray, Anne Marcellini, Sakis Pappous, and Rémi Richard take a critical look at the Paralympic movement from a sociohistorical perspective (Ferez et al., 2020). In critiquing the leveraging effects of Paralympic Games upon grassroots and elite sport participation, the authors utilize the literature to demonstrate that barriers and forms of exclusion depend on the type of disability (e.g., intellectual disability, sensory impairment). Ferez et al. (2020) also highlight that the extent of media coverage of Paralympic performance depends on the disabilities of the athletes. They call for more inclusive and encompassing representations of disabled sporting bodies that moves away from the exclusive and exclusionary coverage of a small number of high-level athletes often framed according to notions of their able-bodiedness.

\section{Acknowledgments}

We would like to thank Ulf Hedetoft (University of Copenhagen, Denmark) and the Editorial Board of Social Inclusion for giving us the opportunity to act as Guest Editors of a thematic issue on the broad theme of sport, development, and social inclusion. A sincere word of gratitude also to António Vieira and Mariana Pires (Cogitatio Press) for their utmost professional approach in coordinating and managing this thematic issue. Their assistance was crucial during the difficult time of the Covid-19 pandemic. Finally, we would like to thank all the authors and reviewers that have contributed to the thematic issue.

\section{Conflict of Interests}

The authors declare no conflict of interests.

\section{References}

Bailey, R. (2005). Evaluating the relationship between physical education, sport and social inclusion. Educational Review, 57(1), 71-90.

Black, D. (2009).The ambiguities of development: Implications for 'development through sport.' Sport in Society, 13(1), 121-129.

Burnett, C. (2015). Assessing the sociology of sport: On sport for development and peace. International Review for the Sociology of Sport, 50(4/5), 385-390.

Coalter, F. (2005). The social benefits of sports: An overview to inform the community planning process (Sportscotland Research Report No. 98). Edinburgh: Sportscotland.

Collins, M. (2002). Sport and social exclusion. London: Routledge.

Collison, H., Darnell, S., Giulianotti, R., \& Howe, P. (Eds.). (2018). Routledge handbook of sport for development and peace. London: Routledge.

Cunningham, R., Bunde-Birouste, A., Rawstorne, P., \& Nathan, S. (2020). Young people's perceptions of the influence of a sport-for-social-change program on their life trajectories. Social Inclusion, 8(3), 162-176. https://doi.org/10.17645/si.v8i3.2828

D’Angelo, C., Corvino, C., Cianci, E., \& Gozzoli, C. (2020). Sport for vulnerable youth: The role of multiprofessional groups in sustaining intersectoral collaboration. Social Inclusion, 8(3), 129-138. https://doi. org/10.17645/si.v8i3.2745

Dagkas, S., \& Armour, K. (2012). Introduction. In S. Dagkas \& K. Armour (Eds.), Inclusion and exclusion through youth sport (pp. 1-6). New York, NY: Routledge.

Darcy, S., Ollerton, J., \& Grabowski, S. (2020). “Why can't I play?": Transdisciplinary learnings for children with disability's sport participation. Social Inclusion, 8(3), 209-223. https://doi.org/10.17645/si.v8i3.2750

Darnell, S. (2012). Sport for development and peace: $A$ critical sociology. London: Bloomsbury.

Donnelly, P., \& Coakley, J. (2002). The role of recreation in promoting social inclusion: Perspectives on social inclusion working paper series. Toronto: Laidlaw Foundation.

Ekholm, D., \& Dahlstedt, M. (2020). (Re)forming the inside/outside: On place as a governable domain through sports-based interventions. Social Inclusion, 8(3), 177-186. https://doi.org/10.17645/si. v8i3.2688

Ferez, S., Ruffié, S., Joncheray, H., Marcellini, A., Pappous, S., \& Richard, R. (2020). Inclusion through sport: A critical view on paralympic legacy from a historical perspective. Social Inclusion, 8(3), 224-235. https:// doi.org/10.17645/si.v8i3.2735

Haudenhuyse, R. (2017). Introduction to the issue "Sport for social inclusion: Questioning policy, practice and research." Social inclusion, 5(2), 85-90.

Haudenhuyse, R., Theeboom, M., \& Nols, Z. (2012). Sports-based interventions for socially vulnerable youth: Towards well-defined interventions with easyto-follow outcomes. International Review for the Sociology of Sport, 48(4), 471-484 .

Haudenhuyse, R., Buelens, E., Debognies, P., De Bosscher, V., Derom, I., Nols, Z., ... Vertonghen, J. (2018). Belgium: Community sport for development. In $\mathrm{H}$. Collison, S. Darnell, R. Giulianotti, \& P. Howe (Eds.), Routledge handbook of sport for development and peace (pp. 430-441). London: Routledge.

Hayday, E. J., \& Collison, H. (2020). Exploring the contested notion of social inclusion and gender inclusivity within esport spaces. Social Inclusion, 8(3), 197-208. https://doi.org/10.17645/si.v8i3.2755

Kelly, L. (2011). Social inclusion through sports based interventions? Critical Social Policy, 31(1), 126-150.

Kingsley, B., \& Spencer-Cavaliere, N. (2015). The exclusionary practices of youth sports. Social Inclusion, 3(3), 24-38.

Lawson, A. (2005). Empowering people, facilitating community development, and contributing to sustainable development: The social work of sport, exercise, 
and physical education programs. Sport, Education and Society, 10(1), 135-160.

Marlier, M., Constandt, B., Schyvinck, C., De Bock, T., Winand, M., \& Willem, A. (2020). Bridge over troubled water: Linking capacities of sport and nonsport organizations. Social Inclusion, 8(3), 139-151. https://doi.org/10.17645/si.v8i3.2465

Norman, M. (2020). Sport and incarceration: Theoretical considerations for sport for development research. Social Inclusion, 8(3), 187-196. https://doi.org/10. 17645/si.v8i3.2748

Schaillée, H., Haudenhuyse, R., \& Bradt, L. (2019). Community sports and social inclusion: International perspectives. Sport in Society, 22(6), 885-896.

Schulenkorf, N., Sherry, E., \& Rowe, K. (2016). Sport for development: An integrated literature review. Journal of Sport Management, 30(1), 22-39.
Spaaij, R., Magee, J., \& Jeanes, R. (2014). Sport and social exclusion in global society. New York, NY: Routledge.

Sparkes, A., \& Smith, B. (2014). Qualitative research methods in sport, exercise and health: From process to product. London: Routledge.

Verkooijen, K., Super, S., Mulderij, L., de Jager, D., \& Wagemakers, A. (2020). Using realist interviews to improve theory on the mechanisms and outcomes of sport for development programmes. Social Inclusion, 8(3), 152-161. https://doi.org/10.17645/si. v8i3.2747

Williams, P. (2002). The competent boundary spanner. Public Administration, 80(1), 103-124.

Ziai, A. (2013). The discourse of 'development' and why the concept should be abandoned. Development in Practice, 23(1), 123-136.

\section{About the Authors}

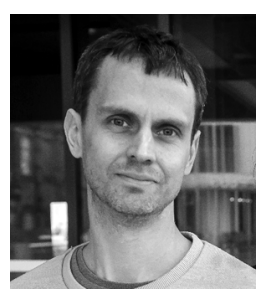

Reinhard Haudenhuyse holds Master's degrees in Physical Education and Third World studies at Ghent University (Belgium). In 2012, he received his PhD in Physical Education and Movement Sciences at the Vrije Universiteit Brussel (Belgium). His research interests revolve around youth, pedagogy, poverty, social in-/exclusion, and the broad field of leisure.

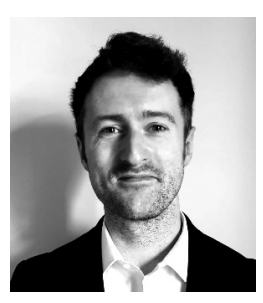

John Hayton is a Senior Lecturer in Sport Development in the Department of Sport, Exercise and Rehabilitation at Northumbria University. John holds a PhD in Sociology and Social Policy from Durham University, UK. John's research interests coalesce around the policy, delivery, and management of sport, leisure, and physical recreation in and by the non-profit and voluntary sector.

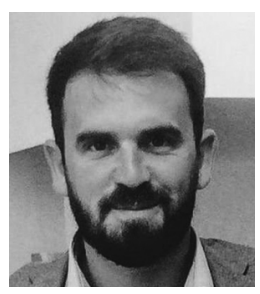

Dan Parnell research interests lies in business management, policy, social and economic networks in sport. Dan serves as Co-Editor-in-Chief of the journal Managing Sport and Leisure, edited a number of books, is a Co-Editor of the Routledge book series Critical Research in Football, and recently co-edited the Routledge Handbook of Football Business and Management. Dan is the Co-Founder of The Football Collective, a global network of football scholars.

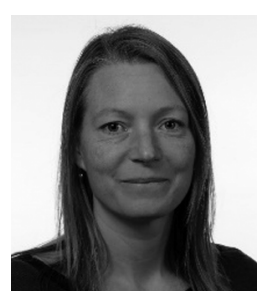

Kirsten Verkooijen is an Assistant Professor at the chair group Health and Society of Wageningen University and Research, in the Netherlands. She wrote her PhD dissertation about the role of selfand social identity in health-related risk behavior among Danish adolescents. Her current research addresses health promotion and health inequalities among socially vulnerable groups, often with a focus on sports and exercise.

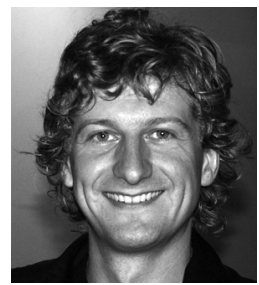

Pascal Delheye studied Physical Education, Sports Management and History in Leuven and Lyon. Following post-doctoral research in Leuven and Berkeley, he was appointed as Professor of Sports History at the Faculty of Movement and Rehabilitation Sciences of the KU Leuven. Since 2017, he is affiliated with the Center for Local Politics at the Faculty of Political \& Social Sciences of Ghent University. As chairholder of the UGent Chair Frans Verheeke (www.thefutureofsport.be), he is focusing on sports policy and politics, intersectoral cooperation, social innovation, inclusion, and empowerment. 